Journal of Engineering and Applied Sciences 14 (Special Issue 7): 10087-10091, 2019

ISSN: 1816-949X

(C) Medwell Journals, 2019

\title{
Physical and Mechanical Properties of Magnesium (Mg) Matrix Composites Reinforced with Carbon Nanotube (CNT) Fabricated by Powder Metallurgy Technique
}

\author{
Hayder Muneam Abed Zaid, Abdul Rahman N. Abed and Hala S. Hasan \\ Department of Mechanical Engineering, Al-Nahrain University, Baghdad, Iraq \\ hayder.munem@gmail.com
}

\begin{abstract}
Multi-Walled Carbon Nanotubes (MWNTs) reinforced magnesium was prepared using a powder metallurgy technique. Powders were mixed by ball milling (without balls) for $6 \mathrm{~h}$ at rotation speed $60 \mathrm{rpm}$. Samples were compacted at $550 \mathrm{MPa}$. And sintered at $530^{\circ} \mathrm{C}$ for $2 \mathrm{~h}$. The magnesium containing $0.1,0.2,0.4$ and 0.6 vol.\% Carbon Nanotubes (CNTs). The physical and mechanical properties such as density, porosity, compressive strength, hardness and wear rate were measured and compared with the unmodified pure magnesium samples values. Results of density referred to the ability to manufacture lightweight composites. The results of mechanical properties revealed that the being of CNTs in the Mg matrix composites significant melioration compressive strength. The best improvement UCS is about (172 $\mathrm{MPa})$ at the volume fraction of 0.4 vol.\% carbon nanotube. The effect of CNTs on the micro Hardness (Hv) values has very limited. The wear tests showed that the wear resistance is increased with the increasing of the reinforcement volume fraction of CNTs.
\end{abstract}

Key words: Reinforced magnesium, metallurgy technique, Carbon Nanotubes (CNTs), micro hardness, mechanical properties, resistance

\section{INTRODUCTION}

Magnesium is the eighth abundant element on Earth, composed of approximately $2.7 \%$ of the weight of the Earth's crust almost (Nayeb-Hashemi and Clark, 1998). Magnesium is one of the lightest engineering materials structural with having a density of $1.74 \mathrm{~g} / \mathrm{cm}^{3}$ (Kulekci, 2008). Its approximately one-fifth lighter than steel and two-third lighter than aluminium is attractive in various applications (Ye and Liu, 2004). It has best ductility, vibration dampening and noise properties compared to aluminum (Jain and Koo, 2007). Rising the drive of lightweight structural materials in aircrafts and automotive vehicles leads to a decrease in energy consumption and environmental impact (Avedesian and Baker, 1999).

At present, the interest in CNTs reinforced MMCs has been increasing. Carbon Nanotubes (CNTs) have extremely high stiffness and their ultra low density in addition to and electrical properties which makes them very charming and suitable for use as reinforcement in composite materials. Using reinforcements CNTs in $\mathrm{MMC}$ manufacturing is very promising because this could be the way for producing lightweight, very high strength and stiff products made out of metal matrix-nanotubes
(Carreno-Morelli et al., 2004). There are several challenges in the manufacture of MMC with CNT reinforcement. By far the most important challenge has been to get a uniform distribution of CNTs in the matrix. CNTs have a big specific surface area up to $200 \mathrm{~m}^{2} / \mathrm{g}$ and hence, they tend to agglomerate and form clusters because of van der Waals forces. Moreover, the non-wetting nature of CNTs to most molten metals results in their clustering. The best dispersion of the reinforcement is a necessity for the efficient use of the (Kondoh et al., 2010) in addition to for obtaining homogeneous properties. CNTs clusters have higher porosity and lower strength serve as discontinuities. Thus, they increase the porosity of the composite. The second important challenge is to ensure the structural and chemical stability of the carbon nanotube in the metal matrix. The best dispersion of the reinforcement is a necessity for the efficient use of the properties in addition to for obtaining homogeneous properties. CNTs clusters have higher porosity and lower strength serve as discontinuities. Thus, they increase the porosity of the composite. The third important challenge is to ensure the chemical and structural stability of the carbon nanotube in the metal matrix. Carbon nanotubes certainly have the potential to produce the strongest composites known to humankind. Many applications have

Corresponding Author: Hayder Muneam Abed Zaid, Department of Mechanical Engineering, Al-Nahrain University, Baghdad, Iraq, hayder.munem@gmail.com 
been projected for CNT metal matrix composites based on the mechanical and functional properties of CNTs. Much research is still underway for overcoming the challenges and comprehension the behavior of these composites (Agarwal et al., 2017).

The number of research papers on $\mathrm{Mg}-\mathrm{CNT}$ composite is less as compared to those in $\mathrm{Cu}, \mathrm{Al}$ and Ni-CNT composites. Mg-CNT composites are being developed largely for improved mechanical properties for structural applications. Some researchers have also focused on the effect of CNTs on the hydrogen storage abilities of $\mathrm{Mg}$ for fuel cell applications. Addition of CNT to $\mathrm{Mg}$ has been done mainly by powder metallurgical and casting route. Most of the studies on metal-CNT composites by the casting method are on Mg-CNT systems (Agarwal et al., 2017).

\section{MATERIALS AND METHODS}

\section{Experimental procedures}

Raw materials: In this study, the matrix material is Magnesium $(\mathrm{Mg})$ powder with average particle size $\sim 59.454 \mu \mathrm{m}$ and the purity percentage was $99 \%$. The density of magnesium powder was $1.738 \mathrm{~g} / \mathrm{cm}^{3}$. Multi Walled Carbon Nanotubes (MWNTs) produced by the Chemical Vapour Deposition (CVD) method has specifications with purity $>95 \mathrm{wt} \%$ outside diameter 20-30 nm, inside diameter 5-10 nm, length 10-30 $\mu \mathrm{m}$ were used as reinforcement phase.

Processing: The powder metallurgy method was used to prepared both magnesium and Magnesium Nanocomposites $(\mathrm{Mg} / \mathrm{CNT})$ with difference containing $0.1,0.2,0.4$ and 0.6 vol\% of carbon nanotubes, respectively. The Balls mill was used roller mixer (without balls) for mixing these powders together in order to get a good dispersion, in which the mixture filled a volume of $50 \%$ from the size of the container 1 vol. $\%$ of stearic acid was added as a process control agent to prevent oxidation of materials, cold welding of particles, reduces the possibility of MWCNTs agglomeration and separation during mixing (Wei et al., 2013). The rotation speed of the cylinders is about $50 \mathrm{rpm}$ for $6 \mathrm{~h}$ (Hassan and Gupta, 2005). Various homogenized powder mixtures of $\mathrm{Mg}$ and carbon nanotubes were then compacted at a pressure of $550 \mathrm{MPa}$ to form a sample of $12 \mathrm{~mm}$ diameter and $9.6 \mathrm{~mm}$ height. The compacted sample were then sintered in under vacuum (non- oxidizing atmosphere) at $530^{\circ} \mathrm{C}$ for $2 \mathrm{~h}$.

Density and porosity measurements: The density was determined by using Archimedes technique (ASTM,
1996) of sintered samples, weighing the sample in air first (Wa) then suspended in distilled water and weighted again (Ww). An monobloc instrument electronic balance with an accuracy of $0.001 \mathrm{~g}$ was used for recording the weights. The density of the composite samples was obtained using the following formula (Anonymous, 2010):

$$
\rho_{\mathrm{ex}}=\frac{\mathrm{Wa}}{\mathrm{Wa}-\mathrm{Ww}} \times \rho_{\mathrm{w}}
$$

where, $\rho_{w}=$ Density of water. The theoretical densities of the samples was calculated using the rule of mixtures as shown following formula (Bhaskar et al., 2016):

$$
\rho_{\text {th }}=\left[\left(f_{\mathrm{CNTs}} \times \rho_{\mathrm{CNTs}}\right)+\left(\mathrm{f}_{\mathrm{Mg}} \times \rho_{\mathrm{Mg}}\right)\right]
$$

The porosity of the specimen was evaluated via. density measurement according to the following formula:

$$
\text { Prosity }=\left(1-\frac{\rho_{\mathrm{ex}}}{\rho_{\mathrm{th}}}\right) * 100 \%
$$

Compression test: Compressive properties of $\mathrm{Mg} 0.1$, $0.2,0.4,0.6 \mathrm{Mg} / \mathrm{vol} \%$. CNTs composites samples have a ratio of length to diameter equal to $0.8(12 \mathrm{~mm}$ diameter and $9.6 \mathrm{~mm}$ length) were used and strain rate is $5 \times 10^{-3} \mathrm{~m} / \mathrm{m} . \mathrm{min}$ according to ASTM. (1996) a standard. The tests were performed with a device of $25 \mathrm{kN}$ capacity load (CXM500) computerized system (ASTM., 1996 ).

Micro hardness test: Microhardness measurements were made on the polished $\mathrm{Mg}$ and $\mathrm{Mg} / \mathrm{CNT}$ s samples. Vickers microhardness tests were performed by digital micro hardness tester (TH-714) under a ( $25 \mathrm{gf}=0.245 \mathrm{~N})$ test load and dwell time of $15 \mathrm{sec}$ in accordance with Anonymous (2004).

Wear test: The samples were tested using the pin on the disc wear apparatus according to Anonymous (2000). In the apparatus, the sample is installed into the arm which is loaded by specific weights. The sample (pin) comes in touch with the rotating stainless steel disk surfaceas shown in Fig. 1.

The weight method was used to calculate the rate wear of samples. The Mass loss $(\Delta \mathrm{M})$ was divided by the Sliding Distance (SD) and calculated the wear rate by using equation as follows:

$$
\mathrm{WR}=\Delta \mathrm{M} / \mathrm{S} . \mathrm{D} \quad \Delta \mathrm{M}=\mathrm{M} 1-\mathrm{M} 2 \quad \mathrm{~S} . \mathrm{D}=\omega \mathrm{rt}
$$


J. Eng. Applied Sci., 14 (Special Issue 7): 10087-10091, 2019

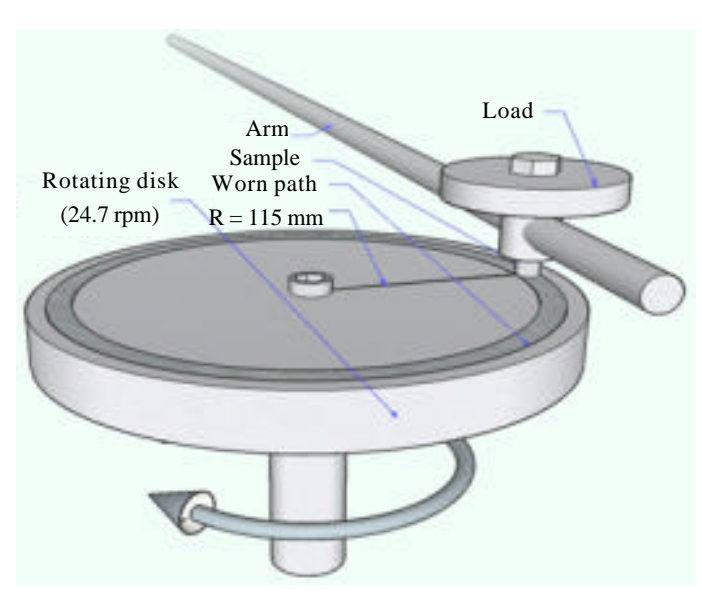

Fig. 1: Diagram of the principle (Pin on disc)

Where:

$\mathrm{WR}=$ The Wear Rate $(\mathrm{g} / \mathrm{m})$

$\Delta \mathrm{M}=$ The Mass losses

$\omega \quad=$ The rotating speed of the disc (rpm)

$\mathrm{r} \quad=$ The disk radius

$\mathrm{t}=$ The slipping time $(\mathrm{min})$

The dimensions of the samples used in this test are of $12 \mathrm{~mm}$ in diameter and $9.6 \mathrm{~mm}$ in length, loaded with three different weights of 5,10 and $15 \mathrm{~N}$ with different sliding distance (100-500 m) and the rotation speed of the steel disc was 243.7 rpm (Fig. 1).

\section{RESULTS AND DISCUSSION}

Porosity and density measurements: Composite material of magnesium with CNTs as showing Table 1 it could be realized that density and the porosity of $\mathrm{Mg} / \mathrm{MWCNTs}$ nano-composites. The porosity level of the nano-composites increases with increasing volume percentages of CNTs. A maximum porosity percentage level of 3.93\% was observed in samples with 0.6 vol.\% CNTs. The porosity in all the nanocomposites is higher than that in pure magnesium. A decrease in the density of the nanocomposites is observed with increasing incorporation of CNTs, this could be due to the increase in porosity in the $\mathrm{Mg}$ matrix or the addition of lighter weight CNTs (Goh et al., 2005).

Density quantification results show that the densities of the $\mathrm{Mg} / \mathrm{CNTs}$ nano-composites are kept at a similar level to that of pure $\mathrm{Mg}$ due to the lightweight properties of the carbon nanotube. This is very engaging because with the addition of ceramic particles as fillers the density of the traditional composites can raise by as much as $11 \%$ (Goh et al., 2006) and this can seriously influence the intent of $\mathrm{Mg}$ being used as a lightweight structural
Table 1: Results of density and porosity of Mg/MWCNTs composites Density $\left(\mathrm{g} / \mathrm{cm}^{3}\right)$

\begin{tabular}{lccc} 
Material (vol.\%.Rei.Mg) & Theoretical & Experimental & Porosity (\%) \\
\hline Magnesium & 1.738 & 1.691 & 2.73 \\
0.1 CNTs & 1.7384 & 1.688 & 2.91 \\
0.2 CNTs & 1.7387 & 1.685 & 3.11 \\
0.4 CNTs & 1.7394 & 1.678 & 3.51 \\
0.6 CNTs & 1.7402 & 1.672 & 3.93 \\
\hline
\end{tabular}

material. The porosity percentage measurement results reveal a limited level of porosity in the $\mathrm{Mg} / \mathrm{CNTs}$ composite specimens, although, the amount detected is up than that in pure Mg.

Compression test: The compression test helps to study the resistance behavior of the composite material to the applied loads. Figure 2 presents the stress-strain curves for $\mathrm{Mg} / \mathrm{CNTs}$ nano composites that have been tested and were placed between the two jaws and compressed until failure.

The addition of multi well carbon nanotube increased the Ultimate Compressive Strength (UCS) above the threshold of 0.4 vol. $\%$ CNT the UCS start to descent. The rising of UCS after addition of CNTs can be attributed to the following known factors relating to reinforcement: dislocation generation because of elastic modulus mismatch and thermal expansion mismatch between the matrix (Mg) and reinforcement (CNTs) (Goh et al., 2006, 2010). Orowan strengthening mechanism. Applied load transfer from matrix to reinforcement (Paramsothy et al., 2011). The restriction of dislocation movement by the CNTs until 0.4 vol.\% of CNTs, above which UCS starts to degenerate due to high expectation of poor interfacial bonding between the carbon nanotube particles and the magnesium metal matrix that is conducive for ineffective applied load transmit from the matrix $(\mathrm{Mg})$ to the reinforcement (CNTs) (Thakur et al., 2007a, b). Incommensurate distribution of the carbon nanotube particles in the magnesium matrix that tends to favor deterioration in the mechanical properties through the nucleation and growth of voids in clustered areas (Thakur et al., 2007a, b). Higher amount of porosity in the $\mathrm{Mg}$ matrix. Or agglomeration of CNTs in metal matrix due to their large specific surface area and van der Waals attraction force makes it the agglomeration. Improvement of ductility was also observed in the compression test of Mg-CNT composites (Goh et al., 2006). The explanation for the increment of ductility in $\mathrm{Mg} / \mathrm{CNT}$ composite was the activation of prismatic slip plane by addition of CNTs. It has shown that the presence of reinforcements can produce a slip mode transition depending on the reinforcement/matrix interaction (Goh et al., 2006) (Fig. 2). 


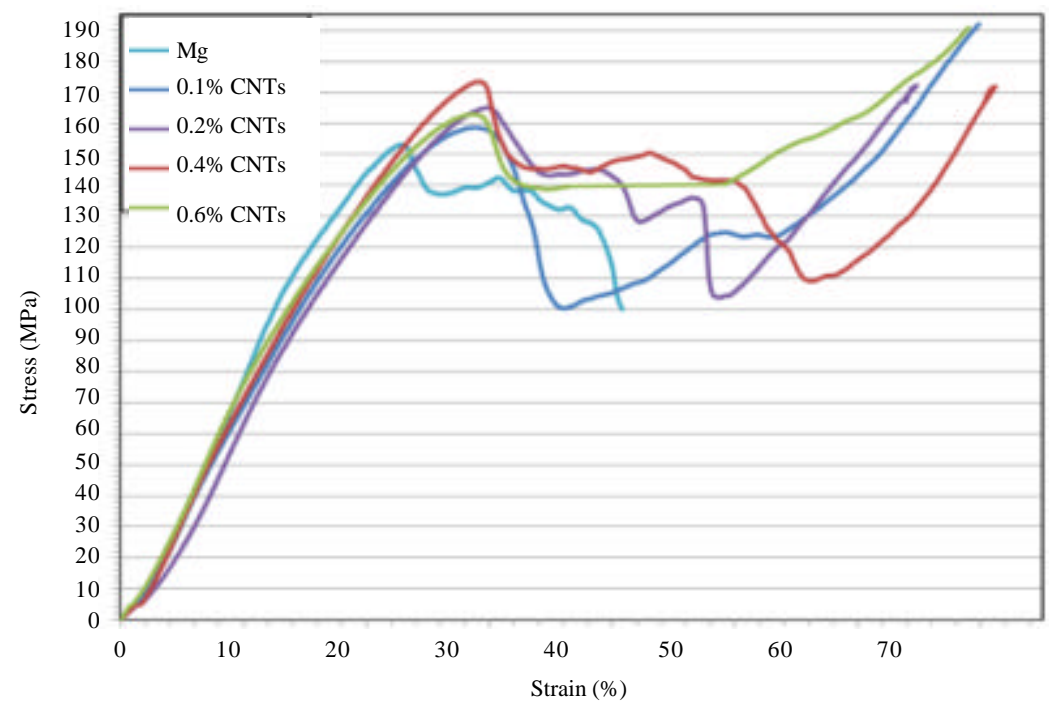

Fig. 2: Stress-strain curves for Mg/CNTs nano composites under compressive loading

Micro hardness: When incorporation of CNTs into the $\mathrm{Mg}$ matrix has a very limited effect on the micro hardness of the nano composites as show in Fig. 3 . This can be attributed to having little contribution to the prevention of localized plastic deformation of the $\mathrm{Mg}$ matrix (Goh et al., 2006) or due to its poorer interfacial adhesion with the $\mathrm{Mg}$ matrix.

For another reason, to the presence of soft CNTs particles. Further increase in CNT content led to a marginal decrease the value of micro-hardness in the case of $\mathrm{Mg} / 0.6 \% \mathrm{CNT}$ due to an increase in the porosity in the $\mathrm{Mg}$ matrix which affects the integrity of the material. The increase in porosity is due to increasing addition of CNT, small clusters of CNTs are a source of porosity in $\mathrm{Mg}$ (Goh et al., 2006).

Wear test: Wear rate results are shown in two diagrams for each group and compared with the pure magnesium. The first diagram illustrates the wear rate as a function of three different applied loads $(5,10$ and $15 \mathrm{~N})$ in the produced composites after $300 \mathrm{~m}$ sliding distance. The second diagram illustrates the wear rate $(\mathrm{g} / \mathrm{m})$ as a function of sliding distance $(\mathrm{m})$ in the produced composites under $10 \mathrm{~N}$ applied loads.

Figure 4 and 5 presents the details of the improvement in wear resistance of $\mathrm{Mg} / \mathrm{CNTs}$ nanocomposite against the sliding distance and applied loads. It could be concluded that improvement in wear resistance with the increment of carbon nanotube content in magnesium-matrix. It has been achieved the best of wear rate resistance at 0.6 vol.\% CNTs. It might be rational to explain the in weight loss to the incorporation the lubrication effect by carbon nanotube played a substantial to condition at the sliding interface between

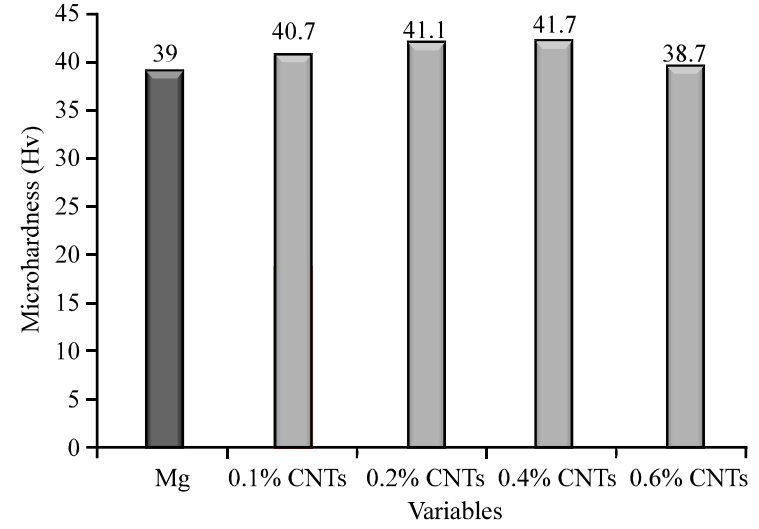

Fig. 3: Micro hardness data of Mg-CNTs composites

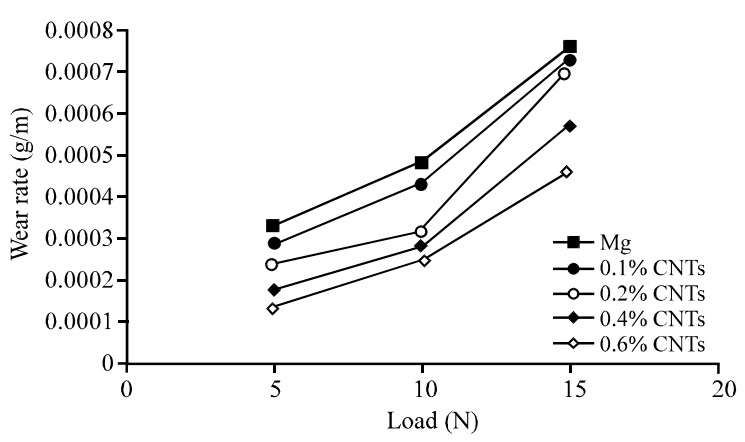

Fig. 4: Wear rate at different applied loads for $\mathrm{Mg} / \mathrm{CNTs}$ nano composite after $300 \mathrm{~m}$ sliding distance

the counterbody and magnesium the because of their network structure on the sliding surface and produce best wear resistance with increase MWCNTs (Wei et al., 2013) (Fig. 5). 


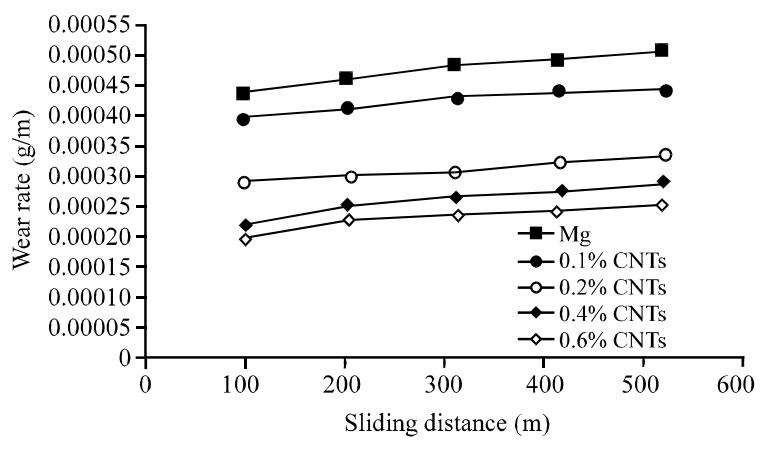

Fig. 5: Variation wear rate with sliding distance for $\mathrm{Mg} / \mathrm{CNTs}$ nano composite under $10 \mathrm{~N}$ applied load

\section{CONCLUSION}

The porosity in all the composites is higher than that in pure magnesium. Where A maximum porosity percentage level of $3.93 \%$ was observed in samples with 0.6 vol.\% CNTs. The nano composite with the volume fraction of 0.4 vol.\% carbon nanotube has higher compressive strength which is about $172 \mathrm{MPa}$. Hardness values of CNTs reinforcement have a very limited effect on the microhardness in the Mg matrix composites. The increasing volume fraction of carbon nanotube will increase the wear resistance of the $\mathrm{Mg} / \mathrm{CNTs}$ composite.

\section{REFERENCES}

ASTM., 1996. ASTM-E9-89a: Standard Test Methods of Compression Testing of Metallic Materials at Room Temperature. ASTM International, West Conshohocken, Pennsylvania, USA.

Agarwal, A., S.R. Bakshi and D. Lahiri, 2017. Carbon Nanotubes: Reinforced Metal Matrix Composites. 1st Edn., CRC Press, Boca Raton, Florida, USA., ISBN:9781138113732, Pages: 325.

Anonymous, 2000. ASTM G99-95a: Standard test method for wear testing with a pin-on-disk apparatus. ASTM International, West Conshohocken, Pennsylvania, USA.

Anonymous, 2004. ASTM B933-04: Standard Test method for microindentation hardness of Powder Metallurgy (P/M) materials. ASTM International, West Conshohocken, Pennsylvania, USA. https://www.astm.org/DATABASE.CART/HISTO RICAL/B933-04.htm

Anonymous, 2010. Standard test methods for apparent porosity, water absorption, apparent specific gravity and bulk density of burned refractory brick and shapes by boiling water1. ASTM International, West Conshohocken, Pennsylvania, USA.

Avedesian, M.M. and H. Baker, 1999. Magnesium and Magnesium Alloys. ASM International, Russell Township, Geauga County, Ohio, USA., ISBN: 9780871706577, Pages: 314.
Bhaskar, S.V., T. Rajmohan, K. Palanikumar and B.B.G. Kumar, 2016. Synthesis and characterization of Multi Wall Carbon NanoTubes (MWCNT) reinforced sintered magnesium matrix composites. J. Inst. Eng. Ser. D., 97: 59-67.

Carreno-Morelli, E., J. Yang, E. Couteau, K. Hernadi and J.W. Seo et al., 2004. Carbon nanotube/magnesium composites. Phys. Status Solidi A., 201: R53-R55.

Goh, C.S., J. Wei, L.C. Lee and M. Gupta, 2005. Development of novel carbon nanotube reinforced magnesium nanocomposites using the powder metallurgy technique. Nanotechnol., 17: 7-12.

Goh, C.S., J. Wei, L.C. Lee and M. Gupta, 2006. Simultaneous enhancement in strength and ductility by reinforcing magnesium with carbon nanotubes. Mater. Sci. Eng. A., 423: 153-156.

Goh, C.S., M. Gupta, A.W. Jarfors, M.J. Tan and J. Wei, 2010. Magnesium and Aluminium carbon nanotube composites. Key Eng. Mater., 425: 245-261.

Hassan, S.F. and M. Gupta, 2005. Development of high performance magnesium nano-composites using nano-A12O3 as reinforcement. Mater. Sci. Eng. A., 392: 163-168.

Jain, C.C. and C.H. Koo, 2007. Creep and corrosion properties of the extruded magnesium alloy containing rare earth. Mater. Trans., 48: 265-272.

Kondoh, K., H. Fukuda, J. Umeda, H. Imai and B. Fugetsu et al., 2010. Microstructural and mechanical analysis of carbon nanotube reinforced magnesium alloy powder composites. Mater. Sci. Eng. A., 527: 4103-4108.

Kulekci, M.K., 2008. Magnesium and its alloys applications in automotive industry. Intl. J. Adv. Manuf. Technol., 39: 851-865.

Nayeb-Hashemi, A.A. and J.B. Clark, 1988. Phase Diagrams of Binary Magnesium Alloys. ASM International, Ohio, USA., ISBN:9780871703286,.

Paramsothy, M., M. Gupta, J. Chan and R. Kwok, 2011. Carbon nanotube addition to simultaneously enhance strength and ductility of hybrid AZ31/AA5083 alloy. Mater. Sci. Appl., 2: 20-29.

Thakur, S.K., G.T. Kwee and M. Gupta, 2007b. Development and characterization of magnesium composites containing nano-sized silicon carbide and carbon nanotubes as hybrid reinforcements. J. Mater. Sci., 42: 10040-10046.

Thakur, S.K., T.S. Srivatsan and M. Gupta, 2007a. Synthesis and mechanical behavior of carbon nanotube-magnesium composites hybridized with nanoparticles of alumina. Mater. Sci. Eng. A., 466: 32-37.

Wei, T.Z., S.R.B. Shamsuri, C.S. Yee, M.W.A. Rashid and Q. Ahsan, 2013. Effect of sliding velocity on wear behavior of magnesium composite reinforced with SiC and MWCNT. Procedia Eng., 68: 703-709.

Ye, H.Z. and X.Y. Liu, 2004. Review of recent studies in magnesium matrix composites. J. Mater. Sci., 39: 6153-6171. 